\title{
Surgical Management of Malignant Melanoma
}

\section{Malign Melanomun Cerrahi Yönetimi}

\author{
Kemal Beksaç ${ }^{1}$, Burcu Beksaç ${ }^{2}$ \\ ${ }^{1}$ Ankara Onkoloji Hastanesi, Genel Cerrahi Ana Bilim Dalı \\ ${ }^{2}$ Gazi Üniversitesi, Dermatoloji Ana Bilim Dalı
}

Dergiye Ulaşma Tarihi:08.01.2016 Dergiye Kabul Tarihi:18.01.2016 Doi 10.5505/aot.2016.73644

\section{ÖZET}

Günümüzde insidansı gittikçe artan malign melanom biyolojisinin anlaşılmasında ve tedavisinde son zamanlarda meydana gelen gelişmelere rağmen, melanom tedavisinde cerrahi yaklaşım önemini korumaktadır. Melanomun cerrahi tedavisinin planlanmasında tümörün histopatolojik özellikleri, anatomik lokalizasyonu, hastanın tercihleri gibi pek çok faktör göz önünde bulundurulmalı ve tedavi her hasta için kişiselleştirilmelidir. Onkolojik tedavi prensiplerini korurken tedavi sonucunu iyileştirmek melanom tedavisindeki asıl amaçtır. Bu makalede malign melanoma cerrahi yaklaşım tartışılmıştır. Tanısal biyopsi, primer ve rekürren tümör eksizyonu, nodal evreleme, ve metastazektomi konularının yanında literatürde fikir birliğine varılamamış alanlar üzerinde durulmuştur. Anahtar Kelimeler: Malign melanom, sentinel lenf nodu örneklemesi, lenf nodu diseksiyonu, metastazektomi Anahtar Kelimeler: Malign Melanom, sentinel lenf nodu biyopsisi, lenf nodu diseksiyonu, metastazektomi

\section{ABSTRACT}

In spite of new developments in the knowledge of the biology of melanoma and its treatment modalities, surgery remains the key treatment modality for malignant melanoma of which the incidence is rising all over the world. Numerous factors such as the histopathologic features of the tumor, its anatomic localization and patient preferences must be considered in the planning of the surgery, and the treatment should be personalized for each patient. Improving the outcome while preserving oncologic treatment principles is the main goal in melanoma treatment. In this article, the authors discuss the surgical approach to malignan melanoma. Topics such as diagnostic biopsy, excision of the primary and recurrent tumors, nodal staging and metastasectomy as well as areas of controversy have been highlighted.

Keywords: Malignant melanoma, sentinel lymph node biopsy, lymph node dissection, metastasectomy

Malign melanom, deri kanseri olgularının $\% 2$ 'sinden azını oluşturmasına rağmen deri kanseri nedenli ölümlerin büyük çoğunluğundan sorumludur. Melanom insidans hızla artmaktadır. Tüm dünyada y1lda 160000 yeni olgu tanı almaktadır (1). Son yillarda bu hastalığın patofizyolojisinin anlaşılması ve tedavisi konusunda önemli gelişmeler kaydedilmesine rağmen günümüzde malign melanom tanıs1, tedavisi ve palyasyonunda en önemli bileșen halen cerrahi yaklaşımdır. Melanomun cerrahi yönetimi, tanısal biyopsiden geniş lokal eksizyon ve nodal evrelemeye kadar titizlikle planlanmalı ve melanom biyolojisi, primer tümörün patolojik özellikleri, tümörün anatomik lokalizasyonu, hastanın tercihleri ve komorbiditeleri, fonksiyonel ve estetik sonuçlar göz önünde bulundurulmalıdır (2). Cerrahi tedavinin temel prensibi ve amac1; primer lezyonun temiz cerrahi sinırlarla eradike edilmesi, tümörün bölgesel yayılımının doğru değerlendirilmesi ve tedavi edilmesi ile hastalıksız sağ kalımı sağlamaktır. Bundan 40 y1l öncesine kadar 3-5 cm cerrahi sınırla eksizyon ve rutin lenf nodu diseksiyonu önerilmekte iken güncel yaklaşımda daha sinırlı rezeksiyon ve sentinel lenf nodu biyopsisi sayesinde hastaların yaklaşık \%80-85'inde lenf nodu diseksiyonu gerekmemektedir (3).

Malign melanomun evrelemesindeki en önemli parametre lezyonun invazyon derinliğidir. İnvazyon derinliğini tanımlamada en çok Breslow kalınlığı ve 
Clark seviyesi kullanılmaktadır. Günümüzde daha çok Breslow kalınlığ 1 kullanılmaktadır. İki sınıflandırma arasındaki fark Tablo 1'de verilmiştir.

\begin{tabular}{|l|l|l|}
\hline Evre & $\begin{array}{l}\text { Clark } \\
\text { seviyesi }\end{array}$ & $\begin{array}{l}\text { Breslow } \\
\text { kalınlığ }\end{array}$ \\
\hline I & $\begin{array}{l}\text { İntra- } \\
\text { epitelyel }\end{array}$ & $<0,76 \mathrm{~mm}$ \\
\hline II & $\begin{array}{l}\text { Papiller } \\
\text { dermis içine } \\
\text { uzanım }\end{array}$ & $0,76-1,5 \mathrm{~mm}$ \\
\hline III & $\begin{array}{l}\text { Dermal } \\
\text { papillayı } \\
\text { dolduran }\end{array}$ & $1,51-2,25 \mathrm{~mm}$ \\
\hline IV & $\begin{array}{l}\text { Retiküler } \\
\text { dermis içine } \\
\text { uzanan }\end{array}$ & $2,26-3 \mathrm{~mm}$ \\
\hline V & $\begin{array}{l}\text { Ciltaltı yağ } \\
\text { dokusuna } \\
\text { uzanım }\end{array}$ & $>3 \mathrm{~mm}$ \\
\hline
\end{tabular}

Tablo1. Clark seviyesi ve Breslow kalınlığı $\quad$ sinıflandırmalarının karşılaştırılması

\section{Tanısal Biyopsi Teknikleri}

Tanısal amaçla kullanılmakta olan 4 farklı biyopsi biçimi vardır: Eksizyonel biyopsi, insizyonel biyopsi, punch biyopsi ve shave biyopsi.

Şüpheli pigmente lezyonların değerlendirilmesinde öncelikle tercih edilen yaklaşım eksizyonel biyopsidir (4,5). Eksizyonel biyopsi ile tümörün invazyon derinliğinin ve hücrelerin mitotik aktivitesi gibi histolojik kriterlerin daha iyi değerlendirilebileceği düşünülmektedir (5). Eksizyonun 1-3 mm sınır ile yapılması tanı ve tedavi planlaması için yeterli kabul edilmektedir.

Günlük pratik uygulamada insizyonel biyopsi, punch biyopsi ve shave biyopsi halen kullanılmaktadır (6). İnsizyonel biyopsi daha çok mukoza, akral bölge ve yüz gibi duyarlı bölgelerde ve lezyonun geniş olması durumunda tercih edilmektedir (7). Biyopsi yönteminin seçimi ile ilgili tartışmaların temelinde sadece tanının konulması değil, tümörün bütünlüğünün bozulması durumunda prognozun olumsuz etkilenebileceği kaygısı da yer almaktadır.

Eksizyonel ve insizyonel biyopsiyi karşılaştıran çok sayıda çalışma olmakla beraber bunların birçoğunda iki biyopsi şekli arasında prognostik açıdan önemli bir fark görülmemiştir (7-9). İnsizyonel biyopsinin etkisini araştıran en büyük seri, İskoçya Melanom Grubunun çalışmasıdır (8). İnsizyonel biyopsi uygulanan 265 hasta, eksizyonel biyopsi uygulanan 496 hasta ile karşılaştırılmış ve biyopsi yönteminin lokal rekürrens ve sağkalıma etkisinin olmadığı gösterilmiştir. Martin ve arkadaşları tarafından yapılan çalışmada (9) ise her dört biyopsi tipi lokal rekürrens, sağkalım ve sentinel lenf nodu mikrometastazları açısından değerlendirilmiş ve arada anlamlı fark saptanmamıştır. Shave biyopsinin de tümör invazyon derinliğini değerlendirmede yeterli olduğunu gösteren çalışmalar mevcuttur (10).

Sonuç olarak; biyopsi için tercih edilmesi gereken teknik cerrahın tercihine, lezyonun boyutu ve yerleşim yerine bağlıdır.

\section{Optimal Cerrahi Sinırın} Belirlenmesi

Melanom tanısı için uygulanan eksizyonel biyopsi sınırını belirlemek için bugüne kadar yapılmış 5 adet randomize kontrollü çalışma vardır:

Dünya Sağlı Örgütü Melanom Programının 8 yılı ve 612 hastayı kapsayan prospektif randomize çalışmasında; invazyon derinliği $2 \mathrm{~mm}$ 'yi geçmeyen lezyonlarda $1 \mathrm{~cm}$ eksizyon sinırı ile $3 \mathrm{~cm}$ ve üzeri eksizyon sınırı sağlanan hastalar karşılaştırılmış, ortalama takip süresi 90 ay olan çalışmada hastalıksız sağkalım ve toplam sağkalım arasında fark görülmemiştir (11).

Intergrup Melanom Çalışmasında; 486 melanom hastası ortalama 6 yıllık süre boyunca takip edilmiş; sadece gövde ve proksimal ekstremitelerde lezyon derinliği 1-4 $\mathrm{mm}$ arası olan hastalar çalışmaya 
alınmış ve $2 \mathrm{~cm}$ veya $4 \mathrm{~cm}$ cerrahi sınır ile eksize edilmiştir. İki grup arasında lokal rekürrens, in-transit metastaz ve 5 y1llık sağkalım oranları açısından fark saptanmamış; $4 \mathrm{~cm}$ cerrahi sınır sağlanan grupta greft kullanım oranı ve hastanede kalış süresinde artış görülmüştür (12).

İsveç Melanom Grubunun çalışmasında; gövde ve üst ekstremitede $0.8-2 \mathrm{~mm}$ lezyonları olan 989 hasta çalışmaya dahil edilmiş ve ortalama 11 yıl süreyle izlenmiştir. $2 \mathrm{~cm}$ ve $5 \mathrm{~cm}$ cerrahi sınırlar karşılaştırılmış, iki grup arasında lokal rekürrens ve sağkalım açısından fark görülmemişsir (13).

Avrupa'da yer alan dokuz merkezi içeren Fransız Malign Melanom çalışma grubunun çalışmasında da İsveç grubuna benzer şekilde 2 ve $5 \mathrm{~cm}$ cerrahi sinırlar karşılaştırılmış, 5 yıllık süre içinde tedavi gören 226 hasta ortalama 16 yıl süreyle takip edilmiştir. Hastaların 10 yıllık sağkalım ve lokal rekürrens oranlarında bu çalışmada da fark saptanmamıştır (14).

İngiliz çalışma grubu tarafından yayınlanan, $2 \mathrm{~mm}$ ve üstü invazyon derinliği olan 900 hastanın dahil edildiği çalışmada $1 \mathrm{~cm}$ ve $3 \mathrm{~cm}$ cerrahi sınırla eksizyon karşılaştırılmış; $1 \mathrm{~cm}$ cerrahi sınır sağlanan grupta lokal rekürrensin daha yüksek olduğu ancak sağkalım açısından fark olmadığı bildirilmiştir (15).

Optimal cerrahi sınırın genişliği konusunda yapılan meta-analiz sonuçları, $2 \mathrm{~cm}$ 'den fazla cerrahi sinırlarla eksizyonun lokal rekürrens ve sağkalım üzerine faydası olmadığını ve cerrahi sınırın $1 \mathrm{~cm}$ 'den az olmaması gerektiğini desteklemektedir (16). İnvazyon derinliği $1 \mathrm{~mm}$ 'den daha az olan melanomlarda $1 \mathrm{~cm}$ cerrahi sinırın yeterli olduğu konusunda fikir birliği olsa da 1-4 mm arasi lezyonlarda ve $4 \mathrm{~mm}$ 'den derin lezyonlarda henüz fikir birliği bulunmamaktadır. Genel olarak, in situ melanomlarda $0,5-1 \mathrm{~cm}, 1 \mathrm{~mm}$ 'den ince tümörlerde (T1) $1 \mathrm{~cm}, 1-2 \mathrm{~mm}$ derinlikteki tümörlerde (T2) 1-2 cm, 2mm'den kalın tümörlerde (T3 ve T4) $2 \mathrm{~cm}$ cerrahi sınır ile eksizyon yapılması tavsiye edilmektedir (4).

\section{Sentinel Lenf Nodu Örneklemesi}

Malign melanomun en s1k metastaz yaptı̆̆ yer bölgesel lenf nodlarıdır ve sentinel lenf nodu tutulumu hastalığın prognozunu etkileyen en önemli faktördür (17). Sentinel lenf nodu biyopsisi metastatik hastalığı belirlemede başarısı yüksek bir yöntem olup orta kalınlıktaki (1-4 mm) melanomlarda yapılması önerilmektedir (17). Desmoplastik melanomlarda, 1 mm'den ince melanomlarda ve $4 \mathrm{~mm}$ 'den kalın melanomlarda sentinel lenf nodu biyopsisinin gerekliliğine dair yeterli kanıt bulunmamaktadir. $1 \mathrm{~mm}$ 'den ince melanomlarda lenf nodu metastazı riski düşük olduğu için sentinel lenf nodu biyopsisi gerekli değildir. 4 mm'den kalın melanomlarda ise evreleme amaciyla ve bölgesel kontrolü sağlamak için yapılabilir (17).

Melanom tedavisinde sentinel lenf nodu biyopsisini değerlendiren prospektif randomize kontrollü çalışmalardan en önemlisi, Çok Merkezli Selektif Lenfadenektomi Çalışması-I (Multicenter Selective Lymphadenectomy Trial-IMSLT-I)'dir (18, 19). Bu çalışmanın birincil amac1 sentinel lenf nodu biyopsisi ile nodal evrelemenin yararını belirlemek, ikinci amacı ise tümör-pozitif sentinel lenf nodu saptandığında erken dönemde yapilacak tamamlayicı lenf nodu diseksiyonunun sağkalıma etkisini saptamaktır. 1994-2002 yılları aras1 tedavi gören 2001 hasta çalışmaya alınmıştır. Hastalar iki gruba randomize edilerek $\%$ 60'ına geniş eksizyon ve rutin sentinel lenf nodu biyopsisi yapılmıştır. Sentinel lenf nodu biyopsisi tümör-pozitif olan hastalara erken dönemde tamamlayıcı lenf nodu diseksiyonu uygulanmıştır. Hastaların \%40'ını oluşturan ikinci grup ise geniş lokal eksizyon yapıldıktan sonra takibe alınmıştır. $\mathrm{Bu}$ olgularda klinik olarak lenf nodu saptandiğında tamamlayıcı lenf nodu diseksiyonu uygulanmıştır. Çalışmaya yalnızca orta 
kalınlıktaki (1,2-3,5mm) melanomlar dâhil edilmiştir. Sentinel lenf nodu biyopsisi uygulanan grubun \%16'sında tümör pozitif lenf nodu saptanmış, bu grupta 10 yıllık takip süresince $\% 4$ olguda daha nodal rekürrens saptanmıştır. Sadece takip uygulanan grupta 5 yıllık takip sürecinde hastaların \%16'sında, 10 y1llik takip sürecinde toplam \%20'sinde nodal rekürrens görülmüştür. Çalışma sonuçlarına göre gruplar arasında 10 yıllık melanoma özgül sağ kalım açısından fark görülmemiş, sentinel lenf nodu biyopsisi uygulanan grupta 10 yıllık hastalıksız sağkalımın daha iyi olduğu belirlenmiştir. Sentinel lenf nodu pozitif olan hastaların sağkalım oranlarının, negatif olanlara göre daha kötü olduğu gösterilmiştir. Sentinel lenf nodu pozitif olup tamamlayıcı lenf nodu diseksiyonu uygulanan hastalarla, takip grubunda yer alıp klinik lenf nodu bulunması durumunda tamamlayıcı lenf nodu diseksiyonu uygulanan hastalar karşılaştırıldığında; sentinel lenf nodu biyopsisi uygulanan grupta hastalıksiz sağkalım ve melanoma özgül sağkalımın daha iyi olduğu saptanmıştır. $\mathrm{Bu}$ çalışmanın sonucuna göre orta kalınlıktaki melanomlarda sentinel lenf nodu biyopsisi hastalıksız sağkalımı, nodal rekürrensi ve uzak metastazı azaltmaktadır. Tecrübeli bir ekip tarafından gerçekleştirildiğinde sentinel lenf nodu biyopsisinin nodal mikrometastazları yakalama başarısının \%95-98 aras1 olduğu bildirilmiştir. Çalışmanın bir diğer önemli bulgusu ise sentinel lenf nodu pozitif olan hastalara lenf nodu diseksiyonu yapıldığında hastaların \%88'inde ikinci bir lenf nodu metastazı saptanmadığıdır. $\mathrm{Bu}$ bulgu, sentinel lenf nodu pozitif olan hastalarda yüksek morbiditeli bir işlem olan lenf nodu diseksiyonundan kaçınabilme olasılığını gündeme getirmiş olması nedeniyle önem taşımaktadır. Bu bulgular ışı̆̆ında MSLTII çalışması dizayn edilmiş ve 2005 yılında başlatılmıştır. Bu çalışma ile sentinel lenf nodu pozitif olan hastalara erken dönemde tamamlayıcı lenf nodu diseksiyonu yapılması ile sadece takip edilmesinin karşılaştırılması hedeflenmiştir (20).

\subsection{Ince Melanomlarda $(<1 \quad \mathbf{m m})$ Sentinel Lenf Nodu Biyopsisi}

İnce melanomlarda sentinel lenf nodu örneklemesi konusunda fikir birliği bulunmamaktadır. Amerika Klinik Onkoloji Topluluğu/Cerrahi Onkoloji Topluluğu (American Society of Clinical Oncology/Society of Surgical OncologyASCO/SSO) tarafindan $1 \mathrm{~mm}$ 'den ince melanomlarda sentinel lenf nodu örneklemesi rutin olarak önerilmemektedir. Bunun yanında ülser varlığı, milimetrekarede birden fazla mitotik aktivite, lezyon kalınlığının 0,75-0,99 mm arasında olması gibi yüksek risk faktörleri varlığında sentinel lenf nodu biyopsisinin uygun olacağ1 belirtilmektedir (17). 0,75 mm'den ince melanomlarda lenf nodu metastaz riski $\% 5$ civarında olduğu için genel olarak sentinel lenf nodu örneklemesi gerekli görülmemektedir (21). Han ve arkadaşlarının çalışmasında 0.75 $\mathrm{mm}-1 \mathrm{~mm}$ aras1 melanomlarda sentinel lenf nodu metastazı hastaların \%8,4'ünde saptanmıştır. T1a hastalarda bu oran $\% 5$ iken T1b hastalarda \%13 olarak bildirilmiş, milimetrekarede birden fazla mitotik aktivite ve ülserasyon varlığında nodal metastaz riskinin yüksek olduğu gösterilmiştir. $\mathrm{Bu}$ nedenle bu çalışmada $0.75 \mathrm{~mm}$ 'den kalın melanomlarda sentinel lenf nodu biyopsisi önerilmiştir (22). Kesmodel ve arkadaşları tarafından da mitotik aktivite varlığında lenf nodu metastaz riskinin yüksek olduğu bildirilmiştir. Kalınlığı $0,75 \mathrm{~mm}$ 'den fazla olan melanomlarda mitotik aktivite bulunduğu zaman lenf nodu metastazı hastaların \%12,3'ünde görülmüştür (21). $\mathrm{Bu}$ çalışmalar $0.75 \mathrm{~mm}$ 'den daha kalın lezyonlar için bilgi vermekle birlikte 0,75 mm'den daha ince olup ülserasyon ya da mitotik aktivite göstermeyen tümörler için literatürde henüz yeterli kanıt yoktur.

\subsection{Kalın Melanomlarda $(>4 \mathrm{~mm})$ Sentinel Lenf Nodu Biyopsisi}


4 mm'den daha kalın lezyonlara sentinel lenf nodu biyopsisi yapılması tartışmalı bir konudur. Kalın melanomlu hastalarda lokal lenf nodu tutulumu ve uzak metastaz riskinin yüksek olduğu bildirilmiştir. Daha önce söz edilen MSLT-I çalışmasında, 3,5 mm'den kalın lezyonu olan 290 hasta değerlendirilmiştir (18). Sentinel lenf nodu biyopsisi yapılan grupta hastaların \%39,9'unda lenf nodu tutulumu görülmüş, takip grubunda 5 ve 10 yıllık lenf nodu metastazı görülme oranları sirasıyla $\% 41$ ve $\% 42$ olarak saptanmış, 10 yıllık hastalıksız sağkalım oranları biyopsi grubunda \%50,7, izlem grubunda \%40,5 olarak bulunmuştur $(\mathrm{HR}, 0,7 ; \mathrm{p}=0.03) . \mathrm{Bu}$ konuyla ilgili olan diğer çalışmalarda da, MSLT-I çalışmasının bulgularına benzer şekilde kalın melanomlarda sentinel lenf nodu biyopsilerinin yaklaşık \%40'1 tümör pozitif olarak saptanmış, sentinel lenf nodu pozitifliğinin prognozu belirlemede en önemli faktör olduğu bildirilmiştir. Sağkalım üzerine net bir fayda gösterilememesine rağmen, prognozu belirlemede önemli katkısı olduğu için kalın melanomlarda sentinel lenf nodu biyopsisi önerilmektedir (23).

\subsection{Desmoplastik Melanomların Tedavisinde Sentinel Lenf Nodu Biyopsisi}

Desmoplastik melanomlarda sentinel lenf nodu biyopsisi, melanom cerrahisi konusunda fikir birliğine varılamamış bir diğer konudur. Desmoplastik melanom kollajen/miksoid stroma içinde malign iğsi melanositlerin proliferasyonu ile karakterizedir. Daha çok yaşı hastalarda görülür ve lokal rekürrens oranları yüksektir. $\mathrm{Bu}$ tümörler genellikle kalın tümörler olmakla birlikte lenf nodu metastazı oranları diğer kalın melanomlardan daha düşüktür (24). Desmoplastik melanomların saf ve mikst olmak üzere iki varyantı vardır. $\mathrm{Bu}$ iki varyant arasindaki sentinel lenf nodu pozitifliği oranları arasında çalışmalar arasında fark bulunmaktadır. Han ve arkadaşları, 205 hastayı değerlendirdikleri çalışmada saf varyantta $\% 9$, mikst varyantta $\% 24,6$ oranında, toplamda $\% 13,7$ sentinel lenf nodu tutulumu saptamışlardır (25). Aynı grubun 2 y1l sonra yayınladığ 1 316 hastay1 kapsayan seride sentinel lenf nodu pozitifliği, saf varyantta $\% 14,6$, mikst varyantta \%26,7 olarak raporlanmıştır (24). Bu çalışmada hastaların \%27,5'inde lokal rekürrens görülmüş ve ölen hastaların \%59,5'i melanoma bağlı sebeplerden ölmüştür. Yüksek sentinel lenf nodu metastaz oranları nedeniyle biyopsi önerilebilecek olsa da, bu gruptaki hastaların ilerde yaşta oldukları düşünüldüğünde komorbiditelerin de göz önünde bulundurulması gerekir. ASCO/SSO desmoplastik melanomlarda sentinel lenf nodu biyopsisini önermektedir (17).

4. Lokal Rekürrenste Tedavi Yaklaşımı

Tıp literatüründe lokal melanom rekürrensi net olarak tanımlanamamış bir kavramdır. Genel olarak lokal rekürrens, uygun cerrahi sınırlar ile gerçekleştirilen definitif cerrahi sonrası insizyon hattı yakınında yeniden lezyon oluşması olarak tanımlanmaktadır. Ancak bu tanım; lokal olarak sebat eden lezyonların yanında lokal metastatik lezyonları da içermektedir. $\mathrm{Bu}$ iki lezyonun patolojik görünümü benzer olmakla birlikte, klinik anlamları farklı olduğundan kavram karmaşasını önlemek için "sebat eden melanom" ve "lokal metastaz" terimleri de önerilmiştir (26).

Lokal rekürrens sıklığı yaklaşık \%4'tür $(15,27)$. İnvazyon derinliği ve ülserasyon rekürrens için kabul edilen risk faktörleridir $(12,27)$. Cerrahi sonrası ilk 5 y1l içinde rekürrens riski daha yüksektir. Distal ekstremitelerde ve yüzde rekürrens görülme olasılığı, proksimal ekstremiteler ve gövdede yerleşen lezyonlara göre daha yüksektir (27).

Cerrahi sınırın $2 \mathrm{~cm}$ 'den fazla olmasının lokal rekürrens sıklığını azaltmadı̆̆ gösterilmiştir (12-15). $1 \mathrm{~cm}$ cerrahi sınırın yeterli lokal kontrol sağlayabileceği halen tartışmalıdır. Lokal rekürrens kötü 
prognoza işaret etmektedir; lokal rekürrens saptanan hastalarda 5 ve 10 yıllık sağkalım oranı yaklaşık $\% 10$ ve $\% 5$ olarak bildirilmiştir (12).

Lokal rekürrens ile başvuran bir hasta detaylı bir fizik incelemeden geçirildikten sonra patolojik tanıyı doğrulamak için biyopsi yapılmalıdır. $\mathrm{Bu}$ hastalarda bölgesel ve uzak metastazlar da olabileceğinden radyolojik inceleme de gereklidir. Tanı doğrulandıktan sonra cerrahiye uygunsa ilk tercih cerrahi olmalıdır. Cerrahi uygulanabilecek hastalarda sentinel lenf nodu örneklemesinin uygun olduğu gösterilmiştir (28). Cerrahinin uygun olmadığ1 hastalarda intratümöral tedavi seçenekleri, izole ekstremite infüzyonu, radyoterapi veya kemoterapi gündeme gelebilir.

\subsection{Lokal Rekürrenste İkinci Kez Sentinel Lenf Nodu Biyopsisi}

Başlangıçta, primer cerrahi sonrası lenfatik akımın değişmiş olabileceği düşüncesiyle lokal rekürrens sonrası sentinel lenf nodu biyopsinin güvenilir olmayabileceği düşüncesi ön planda iken, daha sonraki çalışmalarda durumun böyle olmadığ ortaya çıkmıştır. Beasley ve arkadaşları, lokal rekürrens ve in-transit hastalığı olan 33 hastalık serilerinde lenfosintigrafinin 31 hastada (\%94) başarılı olduğunu göstermişlerdir (29). Aynı çalışmada, 32 hastada (\%97) en az bir sentinel lenf nodu bulunmuş, toplam 10 hastada (\%33) sentinel lenf nodu pozitif olarak saptanmıştır. $\mathrm{Bu}$ bulgular, bu hasta grubunda sentinel lenf nodu biyopsisinin teknik olarak uygun olduğunu göstermede yardımcıdır. Yao ve arkadaşları tarafindan yayınlanan 30 vakalık seride ise 14 hastada (\%47) sentinel lenf nodu pozitif bulunmuş, sentinel lenf nodu pozitif hastaların ortalama sağkalım süreleri (16 ay) ise negatiflere (36 ay) oranla daha belirgin olarak daha kısa olduğu bildirilmiştir (28). Coventry ve arkadaşları ise 12 hastalık serilerinde bütün hastalarda sentinel lenf nodu biyopsisini başarılı bir şekilde uygulamışlardır (30). Bütün bu çalışmalar bize rekürrens ve in-transit hastalık durumunda sentinel lenf nodu örneklemesinin kullanılabileceğini ve sentinel lenf nodu tutulumunun prognostik öneme sahip olduğunu göstermektedir.

\section{Lenf Nodu Diseksiyonu}

Malign melanom tedavisindeki en önemli prognostik faktör lenf nodu tutulumudur. Lenf nodu pozitif hastaların (evre III) tedavisinin en önemli aşaması etkilenmiş lenf nodu bölgesinin tam diseksiyonudur (31). Evre III hastalık mikroskopik ve makroskopik hastalık olarak iki grupta değerlendirilir:

\subsection{Mikroskopik Hastalık}

Klinik olarak palpabl lenf nodu bulunmayıp, sentinel lenf nodu biyopsisi sonucu tanı konulan gruptur ve mikrometastatik hastalı olarak da tanımlanır. Bunun haricinde Amerikan Birleşik Kanser Komisyonu (American Joint Comission for Cancer-AJCC) öncelikle meme kanserinde evreleme sistemini değiştirerek $0,2 \mathrm{~mm}$ 'den daha küçük sentinel lenf nodu metastazlarını izole tümör hücreleri olarak evreleme sistemine sokmuştur. Meme kanserinden sonra malign melanomlarda da bu tanım kullanıma girmiştir. İlk başlarda bu hastaların lenf nodu metastazı olan hastalarla benzer prognozda olduğu düşünülse de, daha sonraki çalışmalar bu grubtaki mortalitenin daha yüksek olduğunu göstermiştir. $\mathrm{Bu}$ gruba tamamlayıc1 lenf nodu diseksiyonu önerilmektedir(32).

Mikrometastatik olan hastaların yaklaşık \%15-20'sinde başka metastatik lenf nodları da olduğu gösterilmiştir $(33,34)$. Sentinel lenf nodu pozitif gelen hastalara tamamlayic1 lenf nodu diseksiyonu önerilmektedir. MSLT-I çalışması da bunu desteklemektedir (18). Yeni tanı almış sentinel lenf nodu pozitif hastalarda bilgisayarlı tomografi, magnetik rezonans gibi radyolojik görüntüleme yöntemlerinin 
sistemik metastazları belirlemede faydası olmadığı gösterilmiştir $(34,35)$.

\subsection{Makroskopik Hastalık}

Makroskopik hastalık, klinik muayenede ele gelen lenf nodu bulunan hastaları tanımlar. $\mathrm{Bu}$ hastalarda prognoz, mikroskobiklenf nodu tutulumu saptanan hastalara göre daha kötüdür $(36,37)$. Klinik ve radyolojik olarak tanmlanmış lenfadenopatisi olan hastalarda metastaz tanısı ince iğne aspirasyon biyopsisi ile doğrulanmalıdır. Hastalığın histolojik olarak doğrulanması için ince iğne aspirasyon biyopsisinden çok eksizyonel biyopsi tercih edilir (18). Makroskopik hastalık tanısı alan hastalarda cerrahi müdahale öncesi başka metastaz olup olmadığını kontrol etmek için bilgisayarlı tomografi, manyetik rezonans görüntüleme, PET/ BT gibi yöntemlerle radyolojik tarama yapılması gerekir.

Uzak metastaz bulunmadiğında, lenf nodu metastazının histolojik olarak doğrulanması durumunda hastalığın yerine ve yayılımına uygun cerrahi müdahale önerilir.

\subsection{Cerrahi Teknikler}

Her ne şekilde tespit edilmiş olursa olsun, lenf nodu tutulumu sonrası öncelikli tedavi cerrahidir. Lenf nodu tutulumu saptandığında cerrahi müdahale yapılan bölgeler servikal, aksiller, inguinal, iliak ve daha nadir olmak üzere epitroklear ve popliteal bölgelerdir. Cerrahi öncesi uygulanan lenfosintigrafi ile başka tutulum odakları da saptanabilir.

\subsubsection{Servikal Lenfadenektomi}

Baş, boyun, üst ekstremite ve gövde üst kısmındaki tümörler sıklıkla boyundaki lenf nodlarına yayılırlar. Level II, III, IV ve V'in dahil edildiği; spinal aksesuar sinir, sternokleidomastoid kas, internal juguler ven korunarak yapilan modifiye radikal boyun diseksiyonu standart cerrahi tedavi şeklidir. Drenajın parotis bezi içinden olduğu veya parotis bezinin içinde lenf nodu tutulumu olduğu durumda yüzeyel parotidektomi de uygulanmalıdır. Dört veya daha fazla boyun bölgesinin dahil olduğu cerrahilerde spesimende en az 20 lenf nodu bulunmalidir (38).

Cerrahi sonrası komplikasyon oranı \%10 dolayındadır. En önemli komplikasyonlar aksesuar spinal sinirin zedelenmesi sonucu omuz disfonksiyonu ve torasik duktus yaralanması sonrası gelişen şilöz fistüldür.

5.3.2. Aksiller Lenfadenektomi

Level I-II-III'ün dahil olduğu aksilla diseksiyonu rutin tedavidir ve cerrahi spesimende en az 20 lenf nodunun bulunmas1 gerekir (38). Sentinel lenf nodu pozitif hastaların \%80'inin ikinci bir lenf nodu tutulumu olmadığ 1 için level III diseksiyonun gerekliliği tartışmalıdır. Namm ve arkadaşlarının gerçekleştirdiği çalışmada sadece level I/II diseksiyon yapılan hastalar literatürdeki oranlarla karşılaştırılmış, komplikasyon ve lokal rekürrens oranları benzer bulunmuştur (39). $\mathrm{Bu}$ konuda daha net karar verilebilmesi için MSLT-II çalışmasının verilerinin yorumlanması beklenmektedir (20).

Cerrahi sonrası komplikasyon oranı yaklaşık \%25'tir. Aksilla diseksiyonunun erken dönem sorunu seroma birikmesi ve lenf sıvıs1 birikimidir. $\mathrm{Bu}$ durum yara açılması ve enfeksiyonlarına sebep olabileceği için önem taşır.

5.3.3. İnguinofemoral (Yüzeyel) ve İlioinguinal (Derin) Lenfadenektomi

İnguinal lenf nodu tutulumu olan hastalarda yüzeyel inguinal lenf nodu diseksiyonu tek başına veya derin inguinal lenf nodu diseksiyonu ile birlikte yapılabilir. Diseksiyon ile en az 7 lenf nodunun çıkarılması önerilmektedir (38). Derin diseksiyon, klinik olarak iliak lenf nodu tutulumu olduğunda ya da yüzeyel diseksiyon sirasinda Cloquet lenf nodu tutulumu saptandığında yapılmaktadır (40). Cloquet lenf nodu biyopsisi mikroskopik hastalık varlığında, dördün altında lenf nodu tutulumunda veya klinik lenf nodu tutulumu olmadığında önerilmektedir. Chu ve arkadaşları, tamamlayıcı yüzeyel inguinal diseksiyon sonrası senkron pelvik hastalık görülme oranını \%11,9 olarak 
bildirmiştir (41). Bazı cerrahlar rutin olarak Cloquet lenf nodu örneklemesi yapmamaktadır.

İnguinal diseksiyon sonrası komplikasyon oranı yüksektir ve birçok çalışmada $\% 50$ dolayında olduğu bildirilmiştir. Yara enfeksiyonu, dehisans, seroma oluşumu, cilt flep nekrozu, lenfödem, derin ven trombozu olası komplikasyonlar arasında sayılabilir (42). Yara yeri komplikasyonlarını azaltmak için sartorius kas transpozisyonu gibi teknik modifikasyonlar denenmiş olmakla birlikte, komplikasyonları önlemede çok başarılı olunamamıştır (43). Ancak son dönemde yara yeri komplikasyonlarını engellemek için videoskopik inguinal diseksiyon yapılmaya başlanmıştır. $\mathrm{Bu}$ teknikle yara komplikasyonlarının azaldığ bildirilmiştir (44).

\section{Metastazektomi}

Uzak metastaz geliştikten sonra melanomun tedavisi güç bir hal alır ve prognozu oldukça kötüdür. Evre 4 hastalık geliştikten sonra ortalama sağkalım 7,5 aydır ve 5-yıllık sağkalım oranı $\% 6$ 'dır (45). Bu hasta grubunun tedavisi için konsensus olmamakla beraber temel olarak sistemik medikal tedavi kullanılmaktadır (46). Uzun bir süre boyunca sistemik tedavinin başarı oranı düşük olduğu için sistemik tedavi daha çok palyatif amaçlı yapılmaktaydi. Son zamanlarda gerçekleştirilen birçok çalışmada metatazektominin sağkalım üzerine faydası olduğu belirlenmiştir. İmmünoterapi konusundaki gelişmelerle beraber metastatik hastalığın tedavisinde önemli gelişmeler olmuştur ve cerrahi tedavi bu hasta grubunun yönetiminde önemli bir yer edinmiştir.

Metastatik melanom agresif bir yayılım paterninde olabileceği gibi yavaş büyüyen, oligometastatik paternde de gelişebilir. Bu farklı yayılım paternlerinin altındaki mekanizmalar aydınlatılamamış olmakla birlikte hastalığın yeterince yavaş ilerlediği bazı hastalarda mevcut tümörlerin çıkarılması mümkündür. Ayrıca, tümör yükünün azaltılması ile tümör hücrelerinin yarattığı immünsüpresyon da azalacağından metastazektominin sağkalıma faydası olabileceği düşünülmektedir (47). Altta yatan biyolojik mekanizma ne olursa olsun metastatik hastalık durumunda rezeksiyonun sağkalımı arttırdığı çok sayıda çalışmayla gösterilmiştir $(19,48)$.

Metastazektomi sonrası sonuçları değerlendiren en geniş serilerden biri Evre IV Malign Melanom için Aktif İmmünoterapi Çalışması (Malignant Melanoma Active Immunotherapy Trial for Stage IV-MMAIT-IV)'dır (49). Çalışma 1998 yılında başlamış olup adjuvan melanom aşısı (Canvaxin) ve Bacille Calmette-Guerin (BCG) kombinasyonuyla plasebo ve BCG kombinasyonu karşılaştırılmıştır. Hastalar metastazektomi sonrası bu iki çalışma kolundan birine randomize edilmiştir. İki grup arasında sağkalım açısından fark olma saptanmamakla birlikte her iki grupta da sağkalım, metastazektomi yapılmayan standart tedavi grubuna göre daha yüksek bulunmuştur.

Bir başka çok merkezli çalışma faz II randomize kontrollü Güneybatı Onkoloji Grubu (Southwest Oncology GroupSWOG) çalışmasıdır (S9430). Çalışmaya tamamen rezektabl metastatik hastalığ1 olan 64 hasta dâhil edilmiştir. Ortalama sağkalım 21 ay, 3 ve 4 yıllık sağkalım \%36 ve \%31 olarak bildirilmiştir. Hasta sayıs1 az olmasına rağmen metastazektominin faydasını göstermesi açısından önemli bir çalışmadır (48).

MSLT-I çalışması da metastazektominin faydasını gösteren araştırmalardan biridir $(18,19)$. Bu çalışmanın birincil amacı farklı olsa da hastaları \%55'i metastazektomi yapilan hastalar olup metastazektominin prognoza faydasi olduğu saptanmıştır.

\subsection{Bölgesel Metastazektomi}

6.1.1. M1a

AJCC'nin 2009 yılında yayınladığ evreleme datasına göre metastatik hastalı̆̆ 
olan hastaların yaklaşık \%20'si M1a grubundadır (primer lezyona komşu deri, deri altı doku, normal LDH ile birlikte uzak lenf nodu metastazı saptanan hastalar). Bu hastaların 1 yıllık sağkalım oran1 \%62'dir (50). John Wayne Kanser Enstitüsünün Canvaxin çalışmasında M1a hastalığa metastazektomi yapilması durumunda ortalama sağkalımın 20 ay, 5y1llık sağkalım \%19 olduğu belirtilmiştir. Ayrica Canvaxin uygulanan grupta bu değerler 41 ay ve \%39 olarak bulunmuştur. MSLT-I çalışmasındaki 291 metastatik olgunun 32'sinin (\%10) M1a hastalığ1 mevcuttur. Metastazektomi uygulanan grupta ortalama sağkalım 60 ay, sistemik medikal tedavi alan grupta 12,4 ay bulunmuştur $(18,19)$.

M1a grubu olgulardan deri ve deri alt1 metastazı olanların prognozunun uzak lenf nodu metastazı olanlara göre daha iyi olduğu belirlenmiştir. Bu hastalara ağrı, ülserasyon ve kanama gibi nedenlerden dolay1 palyatif rezeksiyon da gerekebilmektedir. Lenf nodu metastazı durumunda lenf nodu diseksiyonu önerilmekle beraber bunu destekleyen kuvvetli çalışmalar bulunmamaktadır (51). 6.1.2. M1b

Pulmoner sistem metastazı bulunan hastalar M1b grubunu oluşturur. Pulmoner sistem melanom metastazlarin en sik görüldüğü yer olup, bütün metastazların $\% 40$ 'ını oluşturur (52). 1 yıllık sağkalım $\% 50$ civarındadır. MSLT-I çalışmasında M1b grubu hastalara metastazektomi uygulandığında sağkalım 17,9 ay, sistemik tedavi uygulandığında 9,1 ay olarak6.2. saptanmiştır $(18,19)$ Leo ve arkadaşlarının pulmoner metastazektomiden kimlerin en çok faydalanacağını değerlendirdiği araştırmada, komplet metastazektomi yapılanlarda, hastalıksız sağkalımı 36 aydan fazla olanlarda ve izole metastazı olanlarda prognozun en iyi olduğunu saptanmıştır. $\mathrm{Bu}$ grupta 5 ve 10 yıllık sağkalım \%29 ve \%26 olarak bulunmuştur (53).

\subsubsection{M1c}

M1c visseral organ tutulumunu gösterir. MSLT-I çalışmasında metastazektomi uygulanan hastaların ortalama sağkalımı 15 ay, sadece sistemik tedavi alanlarınki 6,3 ay olarak bildirilmiştir $(18,19)$. Ollila ve arkadaşları tarafından yayınlanan olgu serisinde hastaların yaklaşık yarısında gastrointestinal sistem (GIS) metastazlar1 görülmüş, bu hastaların \%70'inde ince barsak tutulumu saptanmıştır. Daha az siklıkla kolon, mide ve rektum tutulumu gelmektedir (54). Aynı grubun daha önceki serisinde GIS metastazlarında cerrahi tedavi uygulanan grupta ortalama sağkalım 48,9 ay; sistemik tedavi alanlarda ve palyatif cerrahi uygulananlarda yaklaşık 5 aydır (55).

Karaciğer metastazlarının cerrahi tedavisi ile ilgili çalışmalar da mevcuttur (56). Faries ve arkadaşlarının çalışmasında ortalama sağkalım 24,8 ay, 5 yıllık sağkalım \%30 olarak saptanmış, uygulanan cerrahi yöntemi sonucu etkilememiştir (32).

Adrenal metastazlar sık görülmese de, bu konuda da çalışmalar literatürde yer almaktadır. En geniş seri MD Anderson Kanser Merkezi tarafından yayınlanmıştır (57). 154 hastalik seride metastazektomi yapılabilen 22 hastada ortalama sağkalım 20,7 ay; cerrahi yapılmayan grupta 6,8 ay olarak saptanmıştır. Senkron metastaz ve yüksek LDH durumunda prognoz daha kötüdür. John Wayne Kanser Enstitüsünün serisinde ise ortalama sağkalım 25,7 ay olarak saptanmıştır (58).

\section{Komplet Rezeksiyon / Sitoredüksiyon} Farkı

Bütün bu çalışmalarda sağkalımı artırdığı belirlenen önemli bir faktör metastazektominin ne kadar tam yapıldığıdır. Meyer ve arkadaşlarının çalışmasında komplet rezeksiyonda ortalama sağkalım 17 ay, sitoredüksiyonda 6 ay bulunmuştur (59). SWOG çalışmasında komplet rezeksiyon her 10 hastadan 9'unda doğru tahmin edilebilmiştir (48). Sistemik tedavinin 
gelişmekte olduğu dönemde metastazektomi de tedavinin önemli bir parçası olmaya devam edecektir.

7. Izole Ekstremite Perfüzyonu

Izole ekstremite perfüzyonu da ekstremite yerleşimli ileri evre melanomların bölgesel kontrolünü sağlamak amacıyla kullanılan

\section{Kaynaklar}

1. Eggermont AM, Spatz A, Robert C. Cutaneous melanoma. Lancet. 2014;383(9919):816-27.

2. Ott PA, Berman RS. Surgical approach to primary cutaneous melanoma. Surg Oncol Clin N Am. 2011;20(1):39-56.

3. Thompson JF, Scolyer RA, Uren RF. Surgical management of primary cutaneous melanoma: excision margins and the role of sentinel lymph node examination. Surgical oncology clinics of North America. 2006;15(2):301-18.

4. Bishop JA, Corrie PG, Evans J, Gore ME, Hall PN, Kirkham N, et al. UK guidelines for the management of cutaneous melanoma. British journal of plastic surgery. 2002;55(1):46-54.

5. Swanson NA, Lee KK, Gorman A, Lee HN. Biopsy techniques. Diagnosis of melanoma. Dermatologic clinics. 2002;20(4):677-80.

6. Tadiparthi S, Panchani S, Iqbal A. Biopsy for malignant melanoma--are we following the guidelines? Annals of the Royal College of Surgeons of England. 2008;90(4):322-5.

7. Lederman JS, Sober AJ. Does biopsy type influence survival in clinical stage I cutaneous melanoma? Journal of the American Academy of Dermatology. 1985;13(6):983-7.

8. Bong JL, Herd RM, Hunter JA. Incisional biopsy and melanoma prognosis. Journal of the American Academy of Dermatology. 2002;46(5):690-4.

9. Martin RC, 2nd, Scoggins CR, Ross MI, Reintgen DS, Noyes RD, Edwards MJ, et al. Is incisional biopsy of melanoma harmful? American journal of surgery. 2005;190(6):913-7.

10. Saco M, Thigpen J. A retrospective comparison between preoperative and postoperative Breslow depth in primary cutaneous melanoma: how preoperative shave biopsies affect surgical management. Journal of drugs in dermatology : JDD. 2014;13(5):531-6.

11. Veronesi U, Cascinelli N. Narrow excision (1$\mathrm{cm}$ margin). A safe procedure for thin cutaneous melanoma. Archives of surgery. 1991;126(4):438-41.

12. Balch CM, Urist MM, Karakousis CP, Smith TJ, Temple WJ, Drzewiecki K, et al. Efficacy of 2-cm surgical margins for intermediate-thickness melanomas (1 to $4 \mathrm{~mm}$ ). Results of a multi-institutional randomized surgical trial. Annals of surgery. 1993;218(3):262-7; discussion 7-9.

13. Cohn-Cedermark G, Rutqvist LE, Andersson R, Breivald M, Ingvar C, Johansson $\mathrm{H}$, et al. Long term results of a randomized study by the Swedish Melanoma Study Group on 2-cm versus 5-cm resection margins for tedavi yöntemlerinden biridir. Tedavinin amacı sistemik yan etkilerden kaçınarak yüksek doz kemoterapi uygulamaktır. $\mathrm{Bu}$ sayede unrezektabl ekstremite tümörü olan hastalara ampütasyona alternatif ekstremite koruyucu bir tedavi seçeneği sunulabilmektedir (60).

patients with cutaneous melanoma with a tumor thickness of 0.8-2.0 mm. Cancer. 2000;89(7):1495-501.

14. Khayat D, Rixe O, Martin G, Soubrane C, Banzet M, Bazex JA, et al. Surgical margins in cutaneous melanoma ( $2 \mathrm{~cm}$ versus $5 \mathrm{~cm}$ for lesions measuring less than 2.1-mm thick). Cancer. 2003;97(8):1941-6.

15. Thomas JM, Newton-Bishop J, A'Hern R, Coombes G, Timmons M, Evans J, et al. Excision margins in high-risk malignant melanoma. The New England journal of medicine. 2004;350(8):757-66.

16. Haigh PI, DiFronzo LA, McCready DR. Optimal excision margins for primary cutaneous melanoma: a systematic review and meta-analysis. Canadian journal of surgery Journal canadien de chirurgie. 2003;46(6):419-26.

17. Wong SL, Balch CM, Hurley P, Agarwala SS, Akhurst TJ, Cochran A, et al. Sentinel lymph node biopsy for melanoma: American Society of Clinical Oncology and Society of Surgical Oncology joint clinical practice guideline. Journal of clinical oncology : official journal of the American Society of Clinical Oncology. 2012;30(23):2912-8.

18. Morton DL, Thompson JF, Cochran AJ, Mozzillo N, Elashoff R, Essner R, et al. Sentinel-node biopsy or nodal observation in melanoma. The New England journal of medicine. 2006;355(13):1307-17.

19. Howard JH, Thompson JF, Mozzillo N, Nieweg OE, Hoekstra HJ, Roses DF, et al. Metastasectomy for distant metastatic melanoma: analysis of data from the first Multicenter Selective Lymphadenectomy Trial (MSLT-I). Annals of surgical oncology. 2012;19(8):2547-55.

20. Morton DL. Overview and update of the phase III Multicenter Selective Lymphadenectomy Trials (MSLT-I and MSLT-II) in melanoma. Clinical \& experimental metastasis. 2012;29(7):699-706.

21. Kesmodel SB, Karakousis GC, Botbyl JD, Canter RJ, Lewis RT, Wahl PM, et al. Mitotic rate as a predictor of sentinel lymph node positivity in patients with thin melanomas. Annals of surgical oncology. 2005; 12(6):449-58.

22. Han D, Yu D, Zhao X, Marzban SS, Messina JL, Gonzalez RJ, et al. Sentinel node biopsy is indicated for thin melanomas $>/=0.76 \mathrm{~mm}$. Annals of surgical oncology. 2012;19(11):3335-42.

23. Gershenwald JE, Mansfield PF, Lee JE, Ross MI. Role for lymphatic mapping and sentinel lymph node biopsy in patients with thick ( $>$ or $=4 \mathrm{~mm}$ ) primary melanoma. Annals of surgical oncology. 2000;7(2):1605.

24. Han D, Han G, Zhao X, Rao NG, Messina JL, Marzban SS, et al. Clinicopathologic predictors of 
survival in patients with desmoplastic melanoma. PloS one. 2015;10(3): 0119716.

25. Han D, Zager JS, Yu D, Zhao X, Walls B, Marzban SS, et al. Desmoplastic melanoma: is there a role for sentinel lymph node biopsy? Annals of surgical oncology. 2013;20(7):2345-51.

26. MacCormack MA, Cohen LM, Rogers GS. Local melanoma recurrence: a clarification of terminology. Dermatologic surgery : official publication for American Society for Dermatologic Surgery [et al]. 2004;30(12 Pt 2):1533-8.

27. Karakousis CP, Balch CM, Urist MM, Ross MM, Smith TJ, Bartolucci AA. Local recurrence in malignant melanoma: long-term results of the multiinstitutional randomized surgical trial. Annals of surgical oncology. 1996;3(5):446-52.

28. Yao KA, Hsueh EC, Essner R, Foshag LJ, Wanek LA, Morton DL. Is sentinel lymph node mapping indicated for isolated local and in-transit recurrent melanoma? Annals of surgery. 2003;238(5):743-7.

29. Beasley GM, Speicher P, Sharma K, Seigler H, Salama A, Mosca P, et al. Efficacy of repeat sentinel lymph node biopsy in patients who develop recurrent melanoma. Journal of the American College of Surgeons. 2014;218(4):686-92.

30. Coventry BJ, Chatterton B, Whitehead F, James C, Gill PG. Sentinel lymph node dissection and lymphatic mapping for local subcutaneous recurrence in melanoma treatment: longer-term follow-up results. Annals of surgical oncology. 2004;11(3 Suppl):203S-7S.

31. Balch CM, Soong SJ, Gershenwald JE, Thompson JF, Reintgen DS, Cascinelli N, et al. Prognostic factors analysis of 17,600 melanoma patients: validation of the American Joint Committee on Cancer melanoma staging system. Journal of clinical oncology : official journal of the American Society of Clinical Oncology. 2001;19(16):3622-34.

32. Scheri RP, Essner R, Turner RR, Ye X, Morton DL. Isolated tumor cells in the sentinel node affect longterm prognosis of patients with melanoma. Annals of surgical oncology. 2007;14(10):2861-6.

33. Lee JH, Essner R, Torisu-Itakura H, Wanek L, Wang H, Morton DL. Factors predictive of tumorpositive nonsentinel lymph nodes after tumor-positive sentinel lymph node dissection for melanoma. Journal of clinical oncology : official journal of the American Society of Clinical Oncology. 2004;22(18):3677-84.

34. Aloia TA, Gershenwald JE, Andtbacka RH, Johnson MM, Schacherer CW, Ng CS, et al. Utility of computed tomography and magnetic resonance imaging staging before completion lymphadenectomy in patients with sentinel lymph node-positive melanoma. Journal of clinical oncology : official journal of the American Society of Clinical Oncology. 2006;24(18):2858-65.

35. Miranda EP, Gertner M, Wall J, Grace E, Kashani-Sabet M, Allen R, et al. Routine imaging of asymptomatic melanoma patients with metastasis to sentinel lymph nodes rarely identifies systemic disease. Archives of surgery. 2004;139(8):831-6; discussion 6-7.

36. Balch CM, Soong SJ, Atkins MB, Buzaid AC, Cascinelli N, Coit DG, et al. An evidence-based staging system for cutaneous melanoma. CA: a cancer journal for clinicians. 2004;54(3):131-49; quiz 82-4.

37. Pan Y, Haydon AM, McLean CA, McDonald PB, Kelly JW. Prognosis associated with cutaneous melanoma metastases. The Australasian journal of dermatology. 2015;56(1):25-8.

38. Spillane AJ, Cheung BL, Stretch JR, Scolyer RA, Shannon KF, Quinn MJ, et al. Proposed quality standards for regional lymph node dissections in patients with melanoma. Annals of surgery. 2009;249(3):473-80. 39. Namm JP, Chang AE, Cimmino VM, Rees RS, Johnson TM, Sabel MS. Is a level III dissection necessary for a positive sentinel lymph node in melanoma? Journal of surgical oncology. 2012;105(3):225-8.

40. Shen P, Conforti AM, Essner R, Cochran AJ, Turner RR, Morton DL. Is the node of Cloquet the sentinel node for the iliac/obturator node group? Cancer journal. 2000;6(2):93-7.

41. Chu CK, Delman KA, Carlson GW, Hestley AC, Murray DR. Inguinopelvic lymphadenectomy following positive inguinal sentinel lymph node biopsy in melanoma: true frequency of synchronous pelvic metastases. Annals of surgical oncology. 2011;18(12):3309-15.

42. Stuiver MM, Westerduin E, ter Meulen S, Vincent AD, Nieweg OE, Wouters MW. Surgical wound complications after groin dissection in melanoma patients - a historical cohort study and risk factor analysis. European journal of surgical oncology : the journal of the European Society of Surgical Oncology and the British Association of Surgical Oncology. 2014;40(10):1284-90. 43. Bartlett EK, Meise C, Bansal N, Fischer JP, Low DW, Czerniecki BJ, et al. Sartorius transposition during inguinal lymphadenectomy for melanoma. The Journal of surgical research. 2013;184(1):209-15.

44. Martin BM, Etra JW, Russell MC, Rizzo M, Kooby DA, Staley CA, et al. Oncologic outcomes of patients undergoing videoscopic inguinal lymphadenectomy for metastatic melanoma. Journal of the American College of Surgeons. 2014;218(4):620-6.

45. Barth A, Wanek LA, Morton DL. Prognostic factors in 1,521 melanoma patients with distant metastases. Journal of the American College of Surgeons. 1995;181(3):193-201.

46. Korn EL, Liu PY, Lee SJ, Chapman JA, Niedzwiecki D, Suman VJ, et al. Meta-analysis of phase II cooperative group trials in metastatic stage IV melanoma to determine progression-free and overall survival benchmarks for future phase II trials. Journal of clinical oncology : official journal of the American Society of Clinical Oncology. 2008;26(4):527-34.

47. Hsueh EC, Gupta RK, Yee R, Leopoldo ZC, Qi $\mathrm{K}$, Morton DL. Does endogenous immune response determine the outcome of surgical therapy for metastatic melanoma? Annals of surgical oncology. 2000;7(3):2328 .

48. Sosman JA, Moon J, Tuthill RJ, Warneke JA, Vetto JT, Redman BG, et al. A phase 2 trial of complete resection for stage IV melanoma: results of Southwest Oncology Group Clinical Trial S9430. Cancer. 2011;117(20):4740-06.

49. Hoshimoto S, Faries MB, Morton DL, Shingai T, Kuo C, Wang HJ, et al. Assessment of prognostic circulating tumor cells in a phase III trial of adjuvant immunotherapy after complete resection of stage IV melanoma. Annals of surgery. 2012;255(2):357-62.

50. Balch CM, Gershenwald JE, Soong SJ, Thompson JF, Atkins MB, Byrd DR, et al. Final version of 2009 AJCC melanoma staging and classification. Journal of clinical oncology : official journal of the 
American Society of Clinical Oncology.

51. Martinez SR, Young SE. A rational surgical approach to the treatment of distant melanoma metastases. Cancer treatment reviews. 2008;34(7):61420.

52. Essner R, Lee JH, Wanek LA, Itakura $\mathrm{H}$, Morton DL. Contemporary surgical treatment of advanced-stage melanoma. Archives of surgery. 2004;139(9):961-6; discussion 6-7.

53. Leo F, Cagini L, Rocmans P, Cappello M, Geel AN, Maggi G, et al. Lung metastases from melanoma: when is surgical treatment warranted? British journal of cancer. 2000;83(5):569-72.

54. Ollila DW, Gleisner AL, Hsueh EC. Rationale for complete metastasectomy in patients with stage IV metastatic melanoma. Journal of surgical oncology. 2011;104(4):420-4.

55. Ollila DW, Essner R, Wanek LA, Morton DL. Surgical resection for melanoma metastatic to the gastrointestinal tract. Archives of surgery. 1996;131(9):975-9; 9-80.

56. Rose DM, Essner R, Hughes TM, Tang PC, Bilchik A, Wanek LA, et al. Surgical resection for metastatic melanoma to the liver: the John Wayne Cancer Institute and Sydney Melanoma Unit experience. Archives of surgery. 2001;136(8):950-5.

57. Mittendorf EA, Lim SJ, Schacherer CW, Lucci A, Cormier JN, Mansfield PF, et al. Melanoma adrenal metastasis: natural history and surgical management. American journal of surgery. 2008;195(3):363-8; discussion 8-9.

58. Haigh PI, Essner R, Wardlaw JC, Stern SL, Morton DL. Long-term survival after complete resection of melanoma metastatic to the adrenal gland. Annals of surgical oncology. 1999;6(7):633-9.

59. Meyer T, Merkel S, Goehl J, Hohenberger W. Surgical therapy for distant metastases of malignant melanoma. Cancer. 2000;89(9):1983-91.

60. Noorda EM, Vrouenraets BC, Nieweg OE, Van Coevorden F, Kroon BB. Isolated limb perfusion: what is the evidence for its use? Annals of surgical oncology. 2004;11(9):837-45. 